\title{
Property-Control of TiNi System Intermetallics and Their Characteristics
}

\author{
Kazuhiro Matsugi*, Takahiro Kashiwagi, Yong-Bum Choi and Gen Sasaki \\ Department of Mechanical Science and Engineering, Graduate School of Engineering, Hiroshima University, \\ Higashi-Hiroshima 739-8527, Japan
}

The martensitic transformation temperature in addition to the tensile strength and oxidation resistance, were able to be estimated in the crystal structure map using both parameters of the bond order and d-orbital energy level of elements, for the design of TiNi shape memory compounds. The ternary $\mathrm{TiNi}-(\mathrm{Cr}, \mathrm{Re}, \mathrm{Fe}, \mathrm{Cu}, \mathrm{Al})$ intermetallics having the objective constructed phase, tensile strength, Ms-temperatures and oxidation resistance, were obtained successfully, by the adjustment of both parameters. It is found that the effectiveness of the d-electrons concept could be judged, for property-control of ternary TiNi intermetallics, as well as metallic materials. [doi:10.2320/matertrans.F-M2011827]

(Received April 5, 2011; Accepted September 7, 2011; Published November 16, 2011)

Keywords: ternary alloy systems, alloy design, cold crucible levitation melting, phase stability, shape-memory alloy application

\section{Introduction}

Among various shape memory alloys, TiNi alloys are the most commercially exploited ones because of their superior shape memory effect and super-elasticity, better mechanical properties, higher corrosion resistance and excellent biocompatibility. ${ }^{1-3)}$ These properties depend greatly on the exact chemical composition, processing history and smallness of undesirably dissolved elements. ${ }^{4)}$ Traditionally, the temperature interval of $\mathrm{Ti}-50 \mathrm{~mol} \% \mathrm{Ni}$ was observed at cryogenic and environmental temperatures. In contrast, currently, the high operation temperature more than $343 \mathrm{~K}$ is required even in home electric appliances, as the application of TiNi system. Further, high strength and oxidation resistance in manufacturing process are also required for current application of $\mathrm{TiNi}^{4}{ }^{4}$

In most cases, methods for the TiNi development are largely dependent on the trial-and-error experiments and some empirical rules. Therefore, the development is so inefficient and also expensive. In order to save cost and time necessary for alloy development, more fundamental approaches based on the solid theory are needed. It is considered that the d-electrons concept proposed by Morinaga et al. ${ }^{5)}$ is one of fundamental approaches. In fact, the high performance metallic materials such as $\mathrm{Ni}, \mathrm{Ti}$, $\mathrm{Al}, \mathrm{Mg}$ and Fe-based alloys, etc. ${ }^{6-10)}$ had been developed successfully, by the d-electrons concept. Therefore, the d-electrons concept may be applied to design of TiNi intermetallic compounds. ${ }^{11)}$

Titanium and its alloying elements are difficult to be combined uniformly in composition as a solid alloy using usual furnaces like arc or induction melting furnaces, because molten $\mathrm{Ti}$ is very chemically reactive at high temperature. To resolve these problems, utilization of the cold crucible levitation melting (CCLM) is very useful. ${ }^{12-14)}$ The alloys can be melted under untouched condition between the melt and melting crucible, which leads to no contaminant from melting crucible. Moreover, titanium alloys with uniform composition can be produced independently from the differ-

*Corresponding author, E-mail: matsugi@hiroshima-u.ac.jp ence in specific gravity or melting point between titanium and its alloying elements, by the diffusion mixing effect of strong stirring due to an electromagnetic force.

In this study, for TiNi intermetallics with ternary alloying elements, the d-electrons concept was also applied to prediction of their (1) tensile strength, (2) transformation temperature and (3) oxidation resistance, as well as the metallic materials. These properties were experimentally measured for the proposed compounds produced by the CCLM technique for the optimization of manufacturing process. Their measured values were compared with their predicted ones, and using the result of this comparison, the effectiveness of this concept was investigated for the property control of TiNi intermetallics.

\section{Determination of Compositions of TiNi-Y (Y: Ternary Alloying Elements)}

\subsection{Parameters used in d-electrons concept}

Two calculated parameters are mainly utilized in the delectrons concept. ${ }^{5,6}$ ) The one is the d-orbital energy level (Md) of alloying transition elements, and the other is the bond order (Bo) that is a measure of the covalent bond strength between atoms. The values of the parameters for each element which were calculated on octahedral cluster model $\left(\mathrm{M}_{2} \mathrm{X}_{4}, \mathrm{M}\right.$ : alloying elements, $\mathrm{X}$ : Ti, using as $\mathrm{M}-\mathrm{Ti}$ compounds), are listed in Table 1.15,16)

The structure map for the M-Ti compound is constructed using the Bo and Md, as shown in Fig. 1. The crystal structure data of intermetallic compounds are taken from the Pearson's Handbook. ${ }^{17)}$ Each crystal structure is distinguished from others using different symbols on the map. The region for B2-type compound may be estimated using the dashed line in Fig. 1. The Md and Bo values of Ti$50 \mathrm{~mol} \% \mathrm{Ni}$ are -1.284 and 0.466 , respectively.

Some properties such as tensile strength, phase stability and plastic deformation mode had been also represented in the Md and Bo diagram as well as the crystal structure, for practical $\mathrm{Ni}$ and Ti-based alloys, etc. ${ }^{7,18,19)}$ In the beginning of this alloy design, both values in the tensile strength and the temperature in start for martensite transformation (Ms- 
Table 1 Bo and Md values for elements. ${ }^{15,16)}$

\begin{tabular}{|c|c|c|c|c|c|}
\hline \multicolumn{2}{|c|}{ Elements } & \multirow{2}{*}{$\begin{array}{c}\mathrm{Bo}(\mathrm{d}-3 \mathrm{~d}) / \mathrm{Md} \\
0.809 / 1.476 \\
\end{array}$} & \multicolumn{2}{|c|}{ Elements } & \multirow{2}{*}{$\begin{array}{l}\mathrm{Bo}(\mathrm{d}-3 \mathrm{~d}) / \mathrm{Md} \\
1.339 /-0.062 \\
\end{array}$} \\
\hline \multirow{7}{*}{$3 d$} & $\mathrm{Ti}$ & & \multirow{3}{*}{$4 d$} & $\mathrm{Tc}$ & \\
\hline & $\mathrm{Cr}$ & $1.189 / 0.385$ & & $\mathrm{Ru}$ & $1.079 /-0.612$ \\
\hline & $\mathrm{Mn}$ & $1.113 / 0.115$ & & $\mathrm{Rh}$ & $0.834 /-1.473$ \\
\hline & $\mathrm{Fe}$ & $0.969 /-0.293$ & \multirow{4}{*}{$5 \mathrm{~d}$} & Hf & $1.051 / 2.034$ \\
\hline & Co & $0.698 /-0.679$ & & $\mathrm{Ta}$ & $1.291 / 1.589$ \\
\hline & $\mathrm{Ni}$ & $0.466 /-1.284$ & & $\mathrm{Re}$ & $1.430 / 0.116$ \\
\hline & $\mathrm{Cu}$ & $0.138 /-2.399$ & & Os & $1.158 /-0.563$ \\
\hline \multirow{2}{*}{$4 d$} & $\mathrm{Nb}$ & $1.240 / 1.325$ & \multirow{2}{*}{ Others } & $\mathrm{Al}$ & $0.358 / 1.105$ \\
\hline & Mo & $1.351 / 0.470$ & & $\mathrm{Si}$ & $0.334 /-0.278$ \\
\hline
\end{tabular}

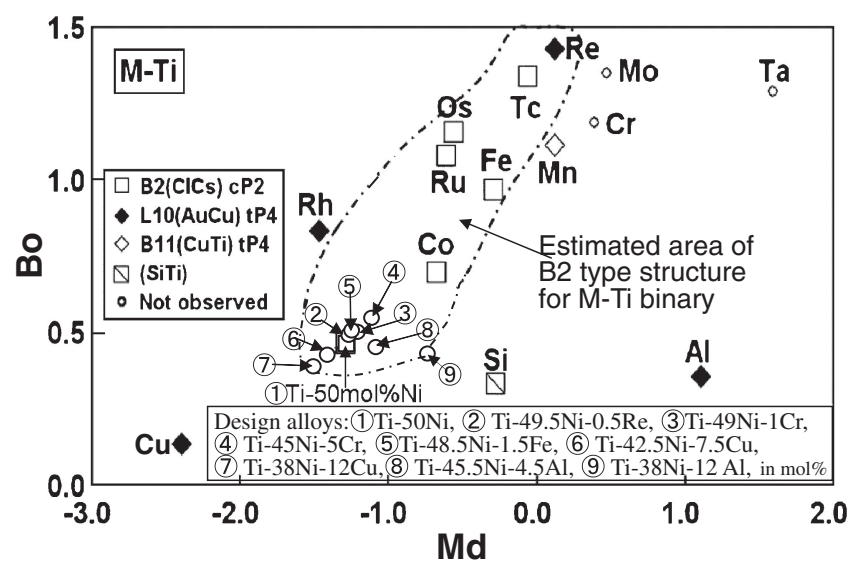

Fig. 1 The Bo-Md structure map ${ }^{15,16)}$ for the M-Ti compounds. Crystal structures are denoted using the Structurbericht symbol and also the Pearson's symbol.

temperature) of previously reported TiNi compounds, ${ }^{20-30)}$ were represented in the $\mathrm{Md}$ and Bo diagram, in order to predict their values of designed intermetallics, as described in the following section 2.2 and 2.3. In addition to binary compounds, ternary (or more multi-components) compounds, for example, $\left(\mathrm{M}_{1-x} \mathrm{Y}_{x}\right) \mathrm{Ti}$ are also located on the Md and Bo map, simply taking the compositional average of the Bo and Md parameters. ${ }^{11)}$ Namely,

$$
\begin{aligned}
\mathrm{Bo} & =(1-x)(\mathrm{Bo})_{\mathrm{M}}+x(\mathrm{Bo})_{\mathrm{Y}} \\
\mathrm{Md} & =(1-x)(\mathrm{Md})_{\mathrm{M}}+x(\mathrm{Md})_{\mathrm{Y}}
\end{aligned}
$$

\subsection{Prediction of tensile strength}

Fifty reported TiNi compounds of compositional range (Ti- $[25 \sim 49] \mathrm{Ni}^{-} \quad[0 \sim 11] \mathrm{Rh}-\quad[0 \sim 5] \mathrm{Ta}-\quad[0 \sim 2] \mathrm{Mo}-$ $[0 \sim 25] \mathrm{Mn}-\quad[0 \sim 3] \mathrm{Co}-\quad[0 \sim 6] \mathrm{Fe}-\quad[0 \sim 12] \mathrm{Al}-\quad[0 \sim 14] \mathrm{Si}-$ $[0 \sim 5] \mathrm{Cr}$ ) in mass $\%,{ }^{20-30)}$ are plotted in the Md-Bo map, as shown in Fig. 2. This figure is duplicated from the estimated region for B2 type structure near Ti-50 mol\% Ni in Fig. 1. The contour lines showing the ultimate tensile strength level of these TiNi system compounds are also estimated by dotted lines, as seen in Fig. 2. The minimum value (350 MPa) of ultimate tensile strength is shown on $\mathrm{Ti}-50 \mathrm{~mol} \% \mathrm{Ni}$, and the contour lines can be approximated as a circle. The tensile strength increases, as the both values of Bo and Md increase in this figure. It is considered that $\mathrm{Fe}, \mathrm{Mn}, \mathrm{Cr}, \mathrm{Re}, \mathrm{Mo}$ and

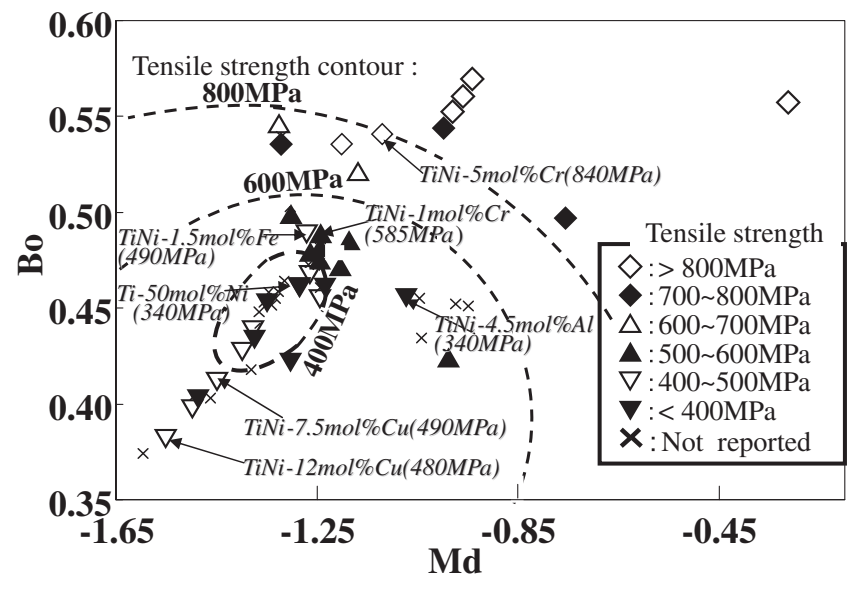

Fig. 2 The Bo-Md map showing the location of the TiNi system compounds reported by various investigators and contour lines of their ultimate tensile strength. Also, the indication of the compositional location and tensile strength of seven intermetallic compounds designed in this study.

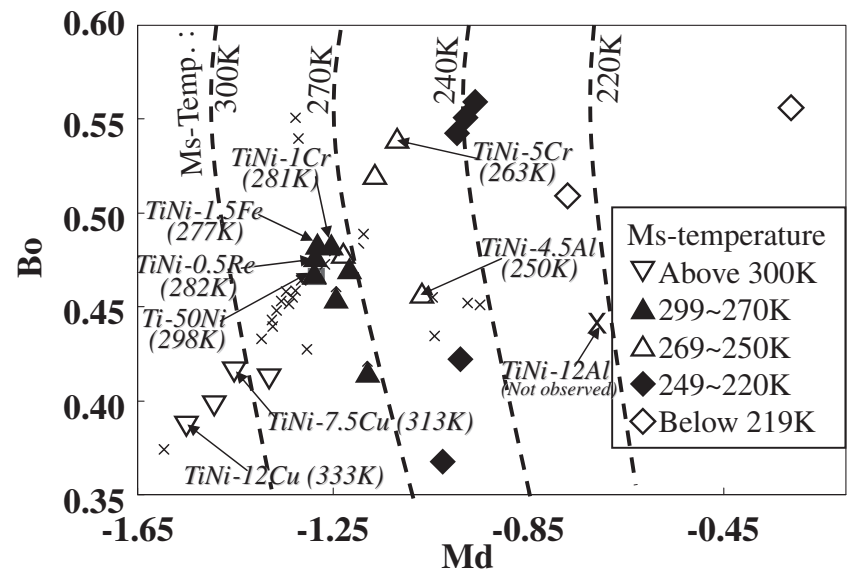

Fig. 3 The Bo-Md map showing the location of the TiNi system intermetallics reported by various investigators and contour lines of their Ms-temperatures. Also, the indication of the compositional location and Ms-temperatures of eight intermetallic compounds designed in this study.

Os, etc. of higher Bo and Md values showing in Fig. 1, are promising elements for the improvement of strength property.

\subsection{Prediction of Ms-temperature}

The contour lines showing the Ms-temperature of these compounds are estimated by dotted lines, as seen in Fig. 3. The Ms-temperature is $298 \mathrm{~K}$ for Ti- $50 \mathrm{~mol} \% \mathrm{Ni}$. The Mstemperatures can be approximated depending on $\mathrm{Md}$ value mainly, which means the control of Ms-temperatures by the adjustment of Md values. The Md-controll is caused by the addition of the suitable alloying elements in TiNi-Y. Namely, it is considered that the addition of $\mathrm{Al}$ and $\mathrm{Cu}$ having higher and lower Md values results in decrease and increase of Mstemperatures, respectively.

\subsection{Prediction of oxidation resistance}

It is well known that for pure metals activation energies for self-diffusion are proportional to the melting points of the 
Table 2 Nominal compositions of experimental intermetallic compounds proposed in this study.

\begin{tabular}{|c|c|c|c|}
\hline Alloy numbers & Compositions (mol\%) & Bo & $\mathrm{Md}$ \\
\hline (1) & $\mathrm{Ti}-50 \mathrm{Ni}$ & 0.466 & -1.284 \\
\hline (2) & $\mathrm{Ti}-49.5 \mathrm{Ni}-0.5 \mathrm{Re}$ & 0.476 & -1.270 \\
\hline (3) & $\mathrm{Ti}-49 \mathrm{Ni}-1 \mathrm{Cr}^{11)}$ & 0.480 & -1.251 \\
\hline (4) & $\mathrm{Ti}-45 \mathrm{Ni}-5 \mathrm{Cr}^{11)}$ & 0.538 & -1.117 \\
\hline (5) & $\mathrm{Ti}-48.5 \mathrm{Ni}-1.5 \mathrm{Fe}$ & 0.481 & -1.254 \\
\hline (6) & $\mathrm{Ti}-42.5 \mathrm{Ni}-7.5 \mathrm{Cu}$ & 0.417 & -1.451 \\
\hline (7) & $\mathrm{Ti}-38 \mathrm{Ni}-12 \mathrm{Cu}$ & 0.387 & -1.552 \\
\hline (8) & $\mathrm{Ti}-45.5 \mathrm{Ni}-4.5 \mathrm{Al}$ & 0.456 & -1.069 \\
\hline (9) & $\mathrm{Ti}-38 \mathrm{Ni}-12 \mathrm{Al}$ & 0.440 & -0.711 \\
\hline
\end{tabular}

metals. ${ }^{31)}$ As the melting point of metals is probably proportional to Bo, the activation energy may be related to Bo. It had been reported that the activation energies for the impurity diffusion in metals also correlate with Bo. ${ }^{32)}$ Moreover, some oxides consisting of $\mathrm{Cr}$ or $\mathrm{Re}$ show excellent oxidation resistance at high temperatures. ${ }^{33)}$ The $\mathrm{Cr}$ and $\mathrm{Re}$ additions in the region for B2-type, are promising due to the higher values in Bo, as shown in Fig. 1.

\subsection{Compositions of proposed alloys}

The target regions of the tensile strength and Ms-temperature for alloy design can be specified concretely on the MdBo diagram, as shown in Figs. 2 and 3. Once a specific MdBo region and a specific alloy system are set in the map, the corresponding alloy composition is simply determined following the rule of the vector sum. ${ }^{18)}$

The Ti-49 mol\% Ni-1 mol\%Cr and Ti-45 mol\% Ni$5 \mathrm{~mol} \% \mathrm{Cr}$ has been designed for the achievement of the high strength of 500 and $800 \mathrm{MPa}$, respectively, ${ }^{11)}$ compared with Ti-50Ni, in the specific Md-Bo region shown in Fig. 2. Hereafter, unless otherwise noted, compound-compositions are referred to in mole per cent. In contrast, the Ti- $48.5 \mathrm{Ni}-$ $1.5 \mathrm{Fe}$ is also designed for the tensile strength of $500 \mathrm{MPa}$, using $\mathrm{Fe}$ of ubiquitous elements. The $\mathrm{Cr}$ addition in $\mathrm{Ti}-50 \mathrm{Ni}$ has been investigated empirically to obtain good mechanical and transformation properties. ${ }^{34,35)}$ The relation between the shape memory ability and damaged layer in the manufacturing process, was also investigated for practical application of Cr containing $\mathrm{TiNi}^{36)}$

In contrast, Ti-38Ni-12Al, Ti-45.5Ni-4.5Al, Ti-49.5Ni$0.5 \mathrm{Re}, \mathrm{Ti}-42.5 \mathrm{Ni}-7.5 \mathrm{Cu}$ and $\mathrm{Ti}-38 \mathrm{Ni}-12 \mathrm{Cu}$ compounds are also designed for the achievement of the various Mstemperatures of $220,250,280,310$ and $320 \mathrm{~K}$, respectively, in the specific Md-Bo region shown in Fig. 3. The control of Ms-temperatures leads to the achievement of the high operation temperature more than $343 \mathrm{~K}$.

The $\mathrm{Cr}$ or $\mathrm{Re}$ addition in Ti-50Ni may result in the good oxidation resistance. The nominal compositions of experimental intermetallic compounds proposed in this study are listed again in Table 2. The alloy numbers in this table correspond to ones of compositional locations of experimental compounds in Fig. 1. In this study, after the determination of alloy compositions, the values of the (1) tensile strength (2) Ms-temperature and (3) oxidation amount which were

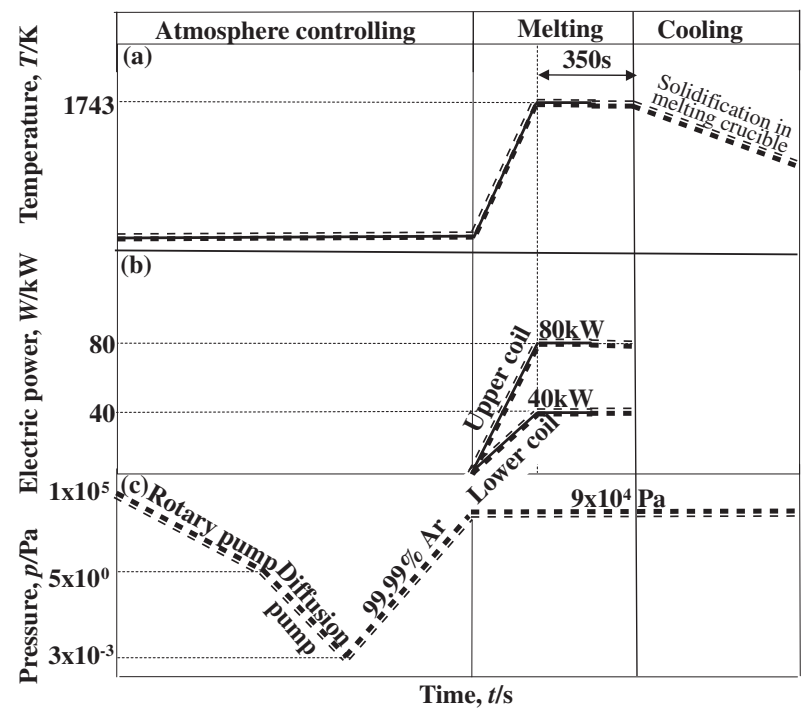

Fig. 4 Profiles of (a) temperature in molten metal, (b) electric power in two coils, and (c) pressure in atmosphere during CCLM process, for preparation of $\mathrm{Ti}-50 \mathrm{Ni}$ ingots.

experimentally measured for nine intermetallics produced by CCLM, were compared with their predicted ones in Figs. 2 and 3.

\section{Experimental Procedures}

All ingots of experimental compounds in this study were prepared from raw materials of pure $\mathrm{Ti}, \mathrm{Fe}, \mathrm{Al}, \mathrm{Cr}, \mathrm{Re}$ and $\mathrm{Ni}$ with 99.7, 99.9, 99.9, 99.9, 99.96 and 99.3 mass\%, respectively, by the CCLM under the atmosphere of argon gas with purity of $99.99 \%$. Each element was inserted in the copper melting crucible with $150 \mathrm{~cm}^{3}$ consisting of 24 segments. The alloys can be melted under untouched condition between melt and melting crucible, which leads to no contaminant from the melting crucible. Figure 4 shows profiles of temperature in molten metal, electric power in upper and lower coils and pressure in atmosphere of a furnace-chamber. The temperature was directly measured by insertion of thermocouples in molten metals. The higher temperature of $1743 \mathrm{~K}$ after the melting of each raw material was kept for $300 \mathrm{~s}$ in melting process, for enough mixing of molten metals. Molten metals were solidified in the copper melting crucible after switching off electric power after the melting process. Chemical compositions of (1) to (9) alloys listed in Table 2 were defined to be Ti-54.9Ni, Ti-53.5Ni-1.7Re, Ti-53.6Ni1Cr, Ti-49.8Ni-5Cr Ti-53.5Ni-1Fe, Ti-45.9Ni-9Cu, Ti$41.7 \mathrm{Ni}-13.4 \mathrm{Cu}$, Ti-51.4Ni-2.4Al and $\mathrm{Ti}-45 \mathrm{Ni}-6.2 \mathrm{Al}$, in mass $\%$. Contents of impurities such as oxygen, carbon and nitrogen in the Ti-50Ni prepared by the CCLM, were 0.046, 0.009 and 0.004 mass $\%$, respectively. The contents of gaseous impurities of oxygen and nitrogen were lower than those (oxygen and nitrogen: 0.069 and 0.006 mass\%, respectively) in the raw materials, because of highly vacuum level as shown in Fig. 4.

Two rods with a diameter of $12 \mathrm{~mm}$ and length of $54 \mathrm{~mm}$ were cut from fixed position in one CCLM ingot by wire electro-discharge machining, EDM, in ion-exchanged water, as shown Fig. 5. All rods were homogeneously heat-treated 


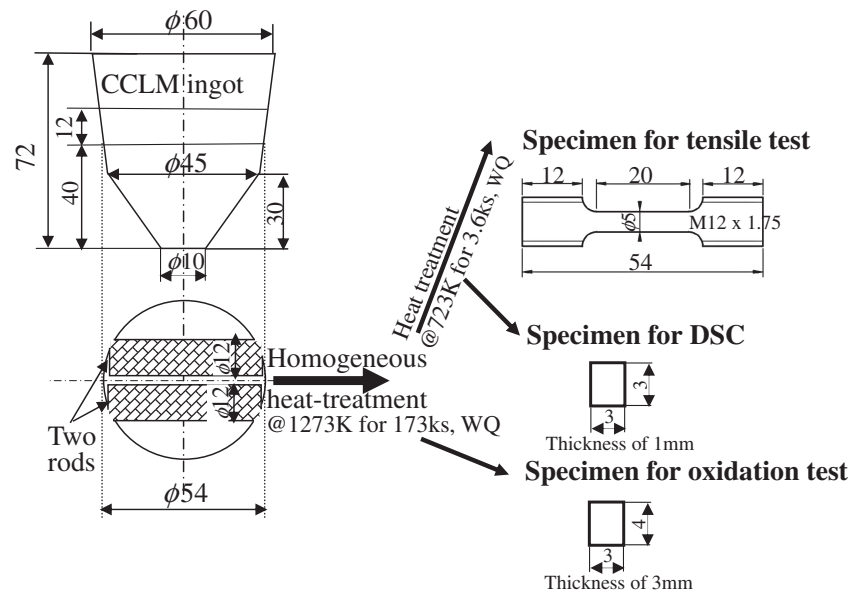

Fig. 5 Schematic representations of the CCLM ingot, showing the cut position of two rods with $12 \mathrm{~mm}$ diameter and $54 \mathrm{~mm}$ length for some specimens such as tensile, oxidation, DSC and microstructure evaluation. Dimensions are given in millimeters.

at $1273 \mathrm{~K}$ for $173 \mathrm{ks}$ in an argon stream and water-quenched for the performance of all following experiments. Transformation behavior was investigated by differential scanning calorimetry (DSC) in the temperature range from 193 to $373 \mathrm{~K}$ at rate of $5 \mathrm{~K} / \mathrm{min}$ in a nitrogen stream. Specimens for tensile tests were heat-treated at $723 \mathrm{~K}$ for $3.6 \mathrm{ks}$ in an argon stream and water-quenched, for the occurrence of shape memory ability. Tensile tests were conducted on selected specimens with gauge diameters of $5 \mathrm{~mm}$ and gauge lengths of $20 \mathrm{~mm}$, at room temperature under an initial strain rate of $5.0 \times 10^{-4} \mathrm{~s}^{-1}$ in air. Oxidation tests at $1273 \mathrm{~K}$ were carried out by a thermo-gravimetric method which meant measurements of weight gain of the specimens exposed in air for $72 \mathrm{ks}$. Size of the oxidation specimen was $3 \times 3 \times 4 \mathrm{~mm}$. $\mathrm{X}$-ray diffraction (XRD) analysis employing nickel filtered $\mathrm{Cu}-\mathrm{K}_{\alpha}$ radiation was performed for phase identification.

\section{Results and Discussion}

\subsection{Microstructures and effects of CCLM}

Some XRD patterns of experimental alloys heat-treated at $1273 \mathrm{~K}$ for $173 \mathrm{ks}$ are shown in Fig. 6. The Cr-, Re-, Fe-added TiNi and Ti-50Ni had B2 or B2 and B19' type structures, depending on Ms-temperatures which were shown below or above room temperature, respectively. In contrast, TiNi-12Cu or TiNi-12Al had also B19 type structure or both $\mathrm{AlNi}_{2} \mathrm{Ti}$ and $\mathrm{Ti}_{2} \mathrm{Ni}$ phases, respectively, in addition to $\mathrm{B} 2$. Three phases of B2, B19' and $\mathrm{Ti}_{2} \mathrm{Ni}$ were identified on TiNi$4.5 \mathrm{Al}$ at the room temperature, although this composition showed the mono phase of $\mathrm{B} 2$ at $1273 \mathrm{~K}^{37}$ )

For Ti-50Ni, TiNi-1Cr, TiNi-5Cr, TiNi-1.5Fe, TiNi$12 \mathrm{Cu}, \mathrm{TiNi}-12 \mathrm{Al}$ and TiNi-0.5Re alloys, their homogeneously heat-treated microstructures are shown in Fig. 7, their grain sizes are 105, 90, 75, 90, 120, 85 and $60 \mu \mathrm{m}$ respectively. These microstructures corresponded to the identified phases obtained from their XRD results. Eight experimental alloys listed in Table 1 had the B2 type structure, regardless of kinds and amount of ternary microalloying elements, except for the TiNi-12Al alloy with the

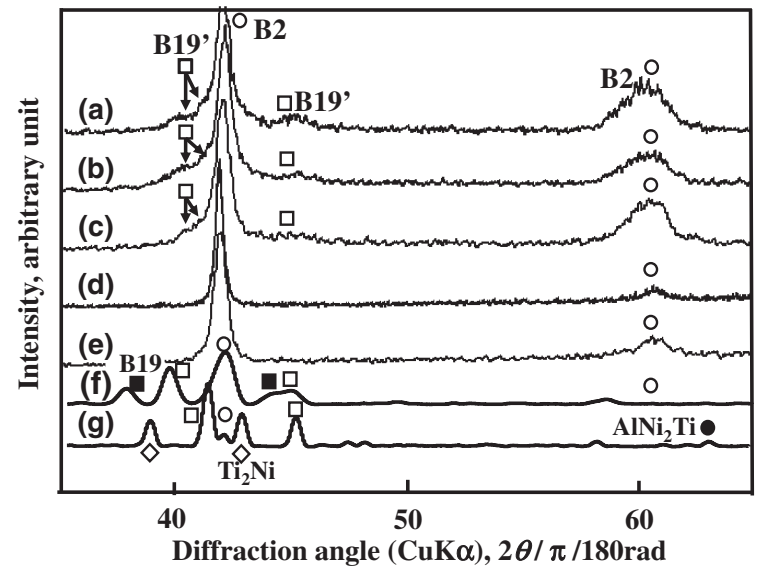

Fig. 6 XRD profiles obtained from homogenized (a) Ti-50Ni, (b) Ti$49.5 \mathrm{Ni}-0.5 \mathrm{Re}$, (c) Ti-48.5Ni-1.5Fe, (d) Ti-45Ni-5Cr, (f) Ti-38Ni-12Cu (g) Ti-38Ni-12Al, and (e) as cast Ti-45Ni-5Cr intermetallic compounds.

$\mathrm{Ti}_{2} \mathrm{Ni}$ and $\mathrm{AlNi}_{2} \mathrm{Ti}$ phases as shown in Fig. 6. As shown in Fig. 1, the ternary alloys in this study are located in the estimated region of B2 type structure on the structure map which is constructed using Bo and $\mathrm{Md}$ for the $3 \mathrm{~d}$ transitionmetal based compound (MTi, M: binary alloying elements). ${ }^{15,16)}$ Any intermetallic compound has more than two sublattices in crystal. So, when a third element is added into the compound, it is first necessary to take into account the substitutional site of the element, and hence attention is directed toward this substitutional problem. It is found that the structure map of binary M-Ti can be also applied for ternary NiTi-Re, -Fe, $\mathrm{Cu}$ and -Cr compounds with compositions proposed in this study, although above substitutional problem can not be clarified for ternary alloying elements.

The XRD pattern of the as-cast TiNi-5Cr is compared with that of the heat treated one, as seen in Fig. 6(d) and (e). Same XRD patterns were observed between both conditions, which meant the better homogenization of molten metal by the diffusion mixing effect of CCLM even for addition of $\mathrm{Cr}$ with higher melting temperatures and densities, compared with other techniques such as induction and arc skull meltings. ${ }^{38)}$

Contents of impurities such as oxygen, carbon and nitrogen in the Ti-50Ni prepared by the CCLM, were $0.046,0.009$ and 0.004 mass \%, respectively, as described in chapter 3 . The contents of gaseous impurities of oxygen and nitrogen were lower than those (oxygen and nitrogen: 0.069 and 0.006 mass $\%$, respectively) in the raw materials. In contrast, there was the same value $(0.009$ mass $\%)$ of the carbon content between the TiNi alloy and raw material. This content of carbon in $\mathrm{TiNi}$ is lower than that $(0.07$ mass $\%)$ in TiNi alloys prepared by vacuum induction melting in the graphite crucible. ${ }^{39)}$ Moreover, it is found from the contents of impurities that the cleanly molten metals were created by utilization of CCLM without the reaction between the molten metal and water-cooled copper crucible, although the affinity of Ti with oxygen, carbon and nitrogen was strong.

\subsection{Transformation temperatures}

Figure 8 shows the typical DSC curves of TiNi, TiNi-1Cr, TiNi-7.5Cu and TiNi-4.5Al alloys. Upper and lower lines represent the exothermic and endothermic curves, respec- 

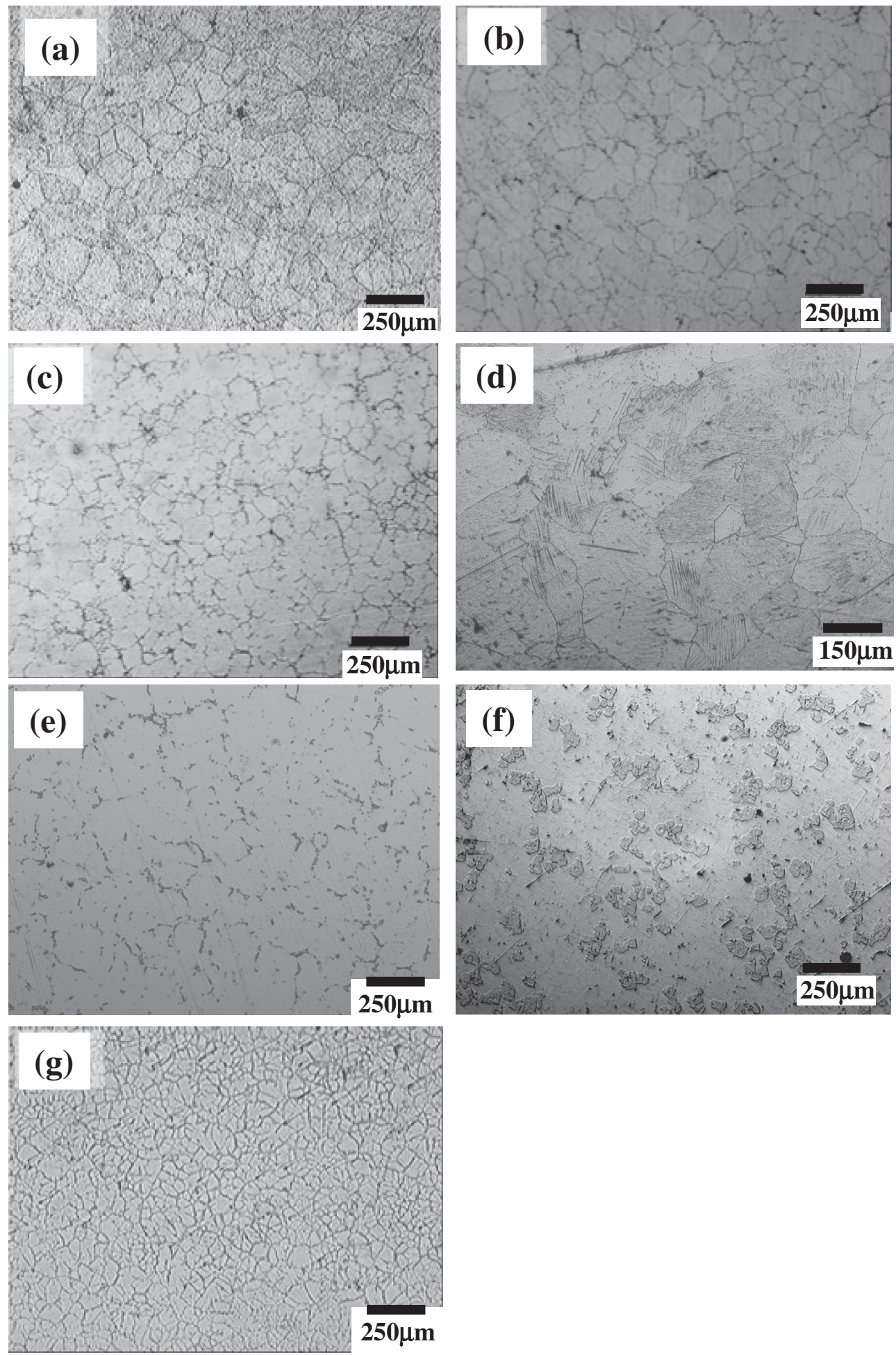

Fig. 7 Optical micrographs showing microstructures after heat-treatment for (a) Ti-50Ni, (b) Ti-49Ni-1Cr, (c) Ti-45Ni-5Cr, (d) Ti$48.5 \mathrm{Ni}-1.5 \mathrm{Fe}$, (e) Ti-38Ni-12Cu, (f) Ti-38Ni-12Al and (g) Ti-49.5Ni-0.5Re intermetallic compounds.

tively. In Ti-50Ni, the transformation on cooling and heating curves occurred in one step from austenite to B19' martensite (A to $\mathrm{M}$ ) and from martensite to austenite ( $\mathrm{M}$ to $\mathrm{A}$ ), respectively. In contrast, two-step transformations on heating and cooling curves were observed on $\mathrm{Cr}$, $\mathrm{Fe}$ and $\mathrm{Re}$ containing alloys. Two steps on heating correspond to the reverse transformations of martensite to $\mathrm{R}$ phase ( $\mathrm{M}$ to $\mathrm{R}$ ) and $\mathrm{R}$ phase to austenite ( $\mathrm{R}$ to $\mathrm{A})$. Moreover, two steps on cooling correspond to austenite to $\mathrm{R}$ phase (A to $\mathrm{R}$ ) and $\mathrm{R}$ to $\mathrm{M}$ transformations. Whereas two transformations on cooling were separated, two reverse transformations on heating overlapped, making it impossible to measure the finish of the $\mathrm{M}$ to $\mathrm{R}$ transformation and the start of the $\mathrm{R}$ to $\mathrm{A}$ transformation. For TiNi-7.5Cu, two-step transformations on heating and cooling curves were observed at higher temperature range. Two steps on heating corresponded to the reverse transformations of $\mathrm{B}^{\prime} 9^{\prime}$ to $\mathrm{B} 19$ phase $\left(\mathrm{M}\right.$ to $\left.\mathrm{M}^{\prime}\right)$ and $\mathrm{M}^{\prime}$ phase to austenite $\left(\mathrm{M}^{\prime}\right.$ to $\left.\mathrm{A}\right)$. Whereas, two reverse 


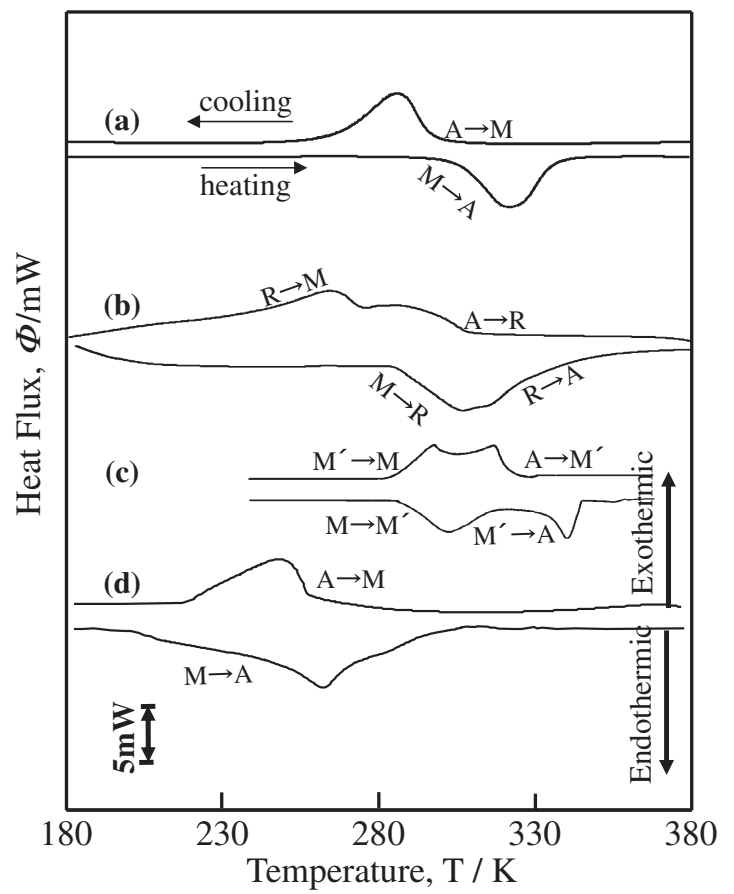

Fig. 8 DSC curves obtained from (a) Ti-50Ni, (b) Ti-49Ni-1Cr, (c) Ti$42.5 \mathrm{Ni}-7.5 \mathrm{Cu}$ and (d) Ti-45.5Ni-4.5Al intermetallic compounds.

Table 3 Some transformation temperatures of experimental intermetallic compounds.

\begin{tabular}{lcccc}
\hline \multirow{2}{*}{$\begin{array}{c}\text { Intermetallic } \\
\text { compounds }\end{array}$} & \multicolumn{4}{c}{ Transformation Temperatures [K] } \\
\cline { 2 - 5 } Ti-50Ni & Ms & Mf & As & Af \\
\hline Ti-49.5Ni-0.5Re & 298 & 263 & 300 & 337 \\
\hline Ti-48.5Ni-1.5Fe & 277 & 258 & 288 & 335 \\
\hline Ti-49Ni-1Cr & 281 & 217 & 284 & 349 \\
\hline Ti-45Ni-5Cr & 263 & 205 & 274 & 324 \\
\hline Ti-42.5Ni-7.5Cu & 313 & 289 & 310 & 353 \\
\hline Ti-38Ni-12Cu & 333 & 312 & 324 & 343 \\
\hline Ti-45.5Ni-4.5Al & 250 & 223 & 187 & 297 \\
\hline
\end{tabular}

transformations overlapped on cooling. Further, the similar transformation behavior to Ti-50Ni was also observed in TiNi-4.5Al. The measured temperatures (Ms, Mf, As and Af) for B19' martensite and austenite transformation were summarized in Table 3. Also, Ms-temperatures of experimental compounds are indicated in Fig. 3. It is found that Ms-temperatures of designed compounds accord with the estimated contour line for ones. This result agrees with the indication for Ms-temperatures of titanium alloys, by both Bo and Md parameters estimating the stability of $\beta$ phase and solubility of alloying elements. ${ }^{5)}$

\subsection{Tensile properties}

The stress-strain curves showing the shape memory ability are shown in Fig. 9, for Ti-50Ni, TiNi-0.5Re, TiNi-1.5Fe, TiNi-1Cr, TiNi-7.5Cu and TiNi-12Cu alloys. Their specimens were strained up to $2 \%$ and then the applied stress was released, because of the ability of strain gauges used in this

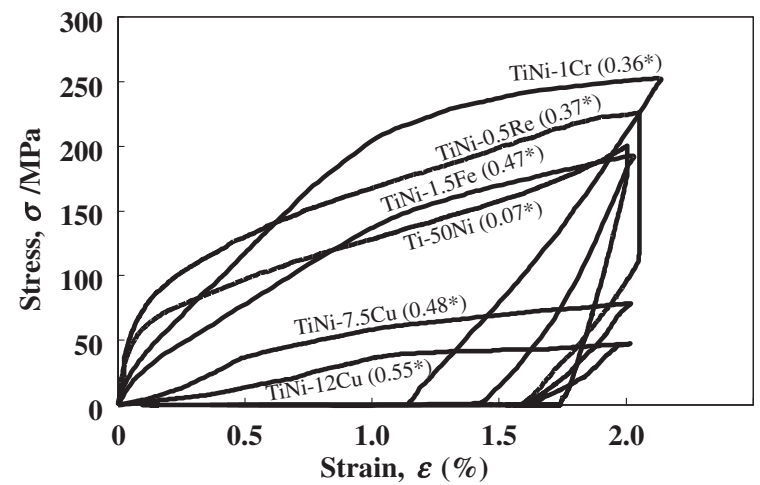

Fig. 9 Stress-strain curves showing the shape memory ability for six experimental intermetallic compounds. *Values of retained strain at $293 \mathrm{~K}$ after the heating above Af.

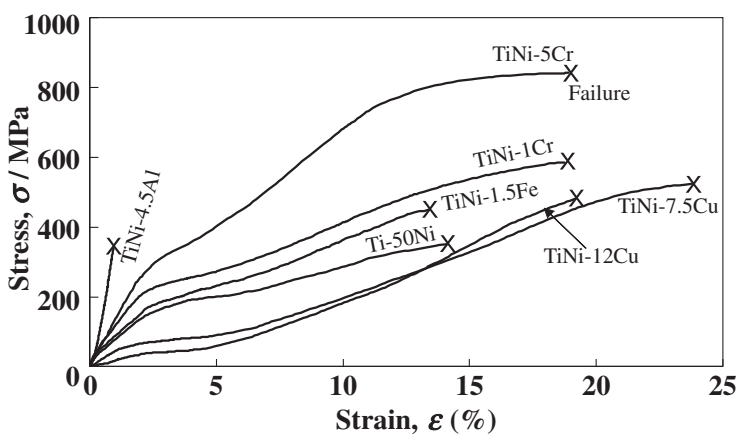

Fig. 10 Stress-strain curves to failure of seven experimental intermetallic compounds.

study. Strains of approximately 1.2 to $1.8 \%$ remained after releasing the applied stress on experimental alloys. Moreover, the rest deformation was recovered with heating above Af (austenite finish) temperatures listed in Table 2. Remained strains of 0.07 to $0.55 \%$ were observed as indicated in each parenthesis in Fig. 9, even after heating above Af temperatures. It is considered on the basis of the results of shape-memory ability that the alloy design can be carried out successfully in the estimated region showing B2 type structure as seen in Fig. 1.

Tensile tests to failure were conducted on $\mathrm{Ti}-50 \mathrm{Ni}$, TiNi1.5Fe, TiNi-1Cr, TiNi-5Cr, TiNi-4.5Al, TiNi-7.5Cu and TiNi-12Cu alloys. Figure 10 shows the true stress-strain curves obtained from these designed intermetallics. Ti-50Ni showed the finally fracture-stress and -elongation of approximately $350 \mathrm{MPa}$ and $13 \%$, respectively. All ternary alloys showed higher fracture-stress and -elongation than binary TiNi, although tensile tests of $\mathrm{Al}$ added alloys were interrupted before completely plastic deformation because of the formation of undesirable $\mathrm{AlNi}_{2} \mathrm{Ti}$ and $\mathrm{Ti}_{2} \mathrm{Ni}$ phase as shown in Figs. 6 and 7. Also, fracture stress or tensile strength of experimental alloys is also indicated in each parenthesis in Fig. 2. The strength of ternary TiNi-X alloys was controlled by the adjustment of both parameters of Bo and $\mathrm{Md}$. It is found that tensile strength of designed intermetallic compounds accord with the estimated contour line for the tensile strength, see Fig. 2. The choice of the high and highly absolute values in Bo and $\mathrm{Md}$ in the B2 area, 


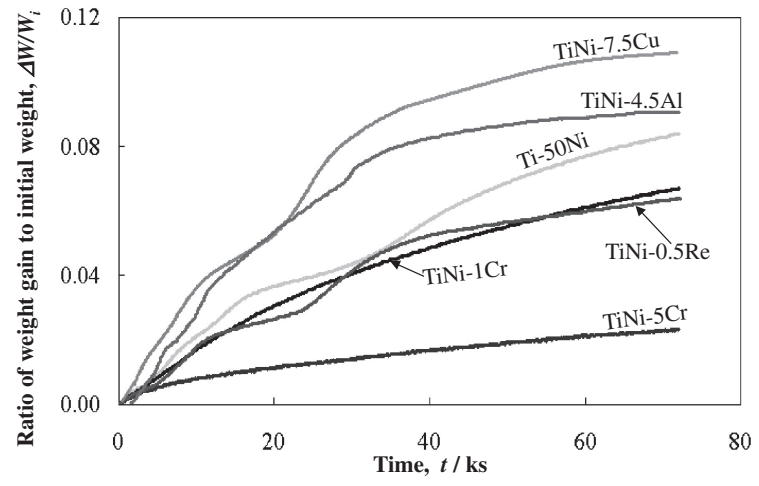

Fig. 11 Kinetic oxidation curves obtained from exposure experiments to $72 \mathrm{ks}$ at $1273 \mathrm{~K}$ for six experimental intermetallic compounds.

respectively, compared with those (Bo: 0.466, Md: -1.284) of $\mathrm{Ti}-50 \mathrm{Ni}$, is promising, because Bo and $\mathrm{Md}$ correspond to covalent bond strength between atoms and the degree of solid-solution hardening or solubility of alloying elements.

\subsection{Oxidation resistance}

The results of oxidation tests at $1273 \mathrm{~K}$ are shown in Fig. 11 for ternary elements-added alloys. The ratio of weight gain to the initial weight of specimens increased as exposed period increased, in all alloys. The accelerated oxidation curves of TiNi, TiNi-0.5Re, TiNi-4.5Al and TiNi$7.5 \mathrm{Cu}$ alloys, showed the complicated shape showing several plateaus. The oxidation was severe initially, settled down for a while, and then was catastrophic again. The severe and moderate oxidation took place alternately, which meant formation of porous $\mathrm{TiO}_{2}$ and $\mathrm{TiO}$ oxides at the interface between alloys and air, and their exfoliation. This agrees with the previously open literature. ${ }^{40)}$ In contrast, the simply oxidation curves without a plateau were obtained on both TiNi-Cr alloys with 1 and $5 \mathrm{Cr}$, which meant formation of densely $\mathrm{Cr}_{2} \mathrm{O}_{3}$ oxide. For TiNi-5Cr, the almost constant value was shown in the weight gain after $72 \mathrm{ks}$, which was caused due to the increase of continuously $\mathrm{Cr}_{2} \mathrm{O}_{3}$ oxide films. Moreover, $\mathrm{TiNi}-5 \mathrm{Cr}$ showed the excellent oxidation resistance and its weight gain after $72 \mathrm{ks}$ was approximately $30 \%$, compared with $\mathrm{Ti}-50 \mathrm{Ni}$.

The apparent activation energy for the initial oxidation of Ti-50Ni was estimated to $180 \mathrm{~kJ} / \mathrm{mol}$ which was close to that $(183 \mathrm{~kJ} / \mathrm{mol})^{41)}$ of oxidation in Ti-2.6Al. In contrast, the values in the apparent activation energy for oxidation of TiNi-5Cr and pure $\mathrm{Cr}$ were estimated to $200 \mathrm{~kJ} / \mathrm{mol}$ in this study and reported to $245 \mathrm{~kJ} / \mathrm{mol},{ }^{42)}$ respectively. $\mathrm{Cr}_{2} \mathrm{O}_{3}$ oxide films are effective for the suppression of oxygendiffusion toward TiNi-Cr alloys, because the activation energy of $\mathrm{TiNi}-5 \mathrm{Cr}$ was estimated as the value between those of $\mathrm{Ti}-50 \mathrm{Ni}$ and pure $\mathrm{Cr}$. The rate in oxidation becomes to small, as the amount in formation of continuously $\mathrm{Cr}_{2} \mathrm{O}_{3}$ oxide films increases in $\mathrm{Cr}$ containing alloys.

Another approach is proposed for the explanation of oxidation behavior. Figure 12 shows the location of designed alloys and their ratios of weight gain to the initial weight of specimens after the $72 \mathrm{ks}$ exposure at $1273 \mathrm{~K}$ as indicated in each parenthesis. There was a good correlation between this ratio and $\mathrm{Bo}$, except for the TiNi-12Al alloy with $\mathrm{B} 2, \mathrm{~B} 19^{\prime}$,

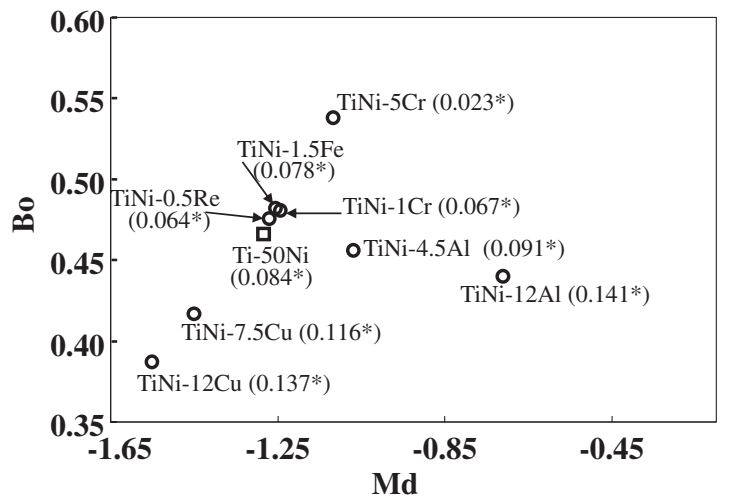

Fig. 12 The location and oxidation resistance of nine experimental TiNi intermetallic compounds on the Bo-Md. ${ }^{*}$ The ratio of weight gain to the initial weight of specimens after the $72 \mathrm{ks}$ exposure at $1273 \mathrm{~K}$ in air.

$\mathrm{AlNi}_{2} \mathrm{Ti}$ and $\mathrm{Ti}_{2} \mathrm{Ni}$ phases. As Bo increased in alloys, this ratio decreased or the oxidation resistance was improved, although there were a few data. It has been found that various physical properties could be interpreted in term of Bo. For example, Bo correlated well with activation energies for impurity-diffusion of transition elements in $\beta$-Ti. ${ }^{32,43)}$ Therefore, the oxidation of intremetallics consisting of same crystal structures may be interpreted by Bo. In contrast, Md is also necessary for the prediction of phase boundary for the achievement of same structure. The result shown in Fig. 12 indicates that an increase in the bond strength between atoms leads to high oxidation resistance. This agrees with the results obtained from the active corrosion rate in $10 \% \mathrm{H}_{2} \mathrm{SO}_{4}$ at $343 \mathrm{~K}^{44)}$ and the weight loss in $\mathrm{Na}_{2} \mathrm{SO}_{4}-45 \mathrm{~mol} \% \mathrm{NaCl}$ molten salt at $923 \mathrm{~K}^{19)}$ for of various Ti alloys.

\subsection{Effectiveness of this concept for property control of TiNi intermetallics}

For TiNi intermetallics with ternary alloying elements of $\mathrm{Cr}, \mathrm{Re}, \mathrm{Fe}, \mathrm{Cu}$ or $\mathrm{Al}$, the tensile strength, Ms-temperature and oxidation amount at high temperature, were measured experimentally. Their measured values in strength and Mstemperature and the order in the oxidation amount were agree with their predicted ones and order, respectively, in the BoMd map. It is found that the effectiveness of the d-electrons concept could be judged, for property-control of TiNi-Y intermetallics, as well as metallic materials.

\section{Conclusions}

For TiNi system intermetallic compounds, their crystal structure, tensile strength, Ms-temperature and oxidation resistance were predicted on the Bo-Md map proposed on the basis of the d-electrons concept. Ternary TiNi intermetallic compounds with $\mathrm{Cr}, \mathrm{Re}, \mathrm{Fe}, \mathrm{Cu}$ and $\mathrm{Al}$ additions were able to be proposed in the specific Bo-Md region. For the designed compounds, their cleanly molten metals with lower contents of $\mathrm{O}, \mathrm{C}$, and $\mathrm{N}$, were created by the utilization of CCLM without the reaction between the molten metal and watercooled copper crucible. The ingots of the designed compounds had the objective constructed phase, tensile strength and Ms-temperatures. The alloying effects in the addition of 
ternary elements in the TiNi intermetallic compounds, were explained by two parameters (Bo, Md). It is found that the effectiveness of the d-electrons concept could be judged, for property-control of TiNi-Y intermetallics, as well as metallic materials.

\section{REFERENCES}

1) K. Otsuka and X. Ren: Intermetallics 7 (1999) 511-528.

2) J. Van Humbeek: Mater. Sci. Eng. A 273-275 (1999) 134-148.

3) T. Durieg, A. Pelton and D. Stockel: Mater. Sci. Eng. A 273-275 (1999) 149-160.

4) K. Matsugi, H. Mamiya, Y. B. Choi, G. Sasaki, O. Yanagisawa and H. Kuramoto: Int. J. Cast Metals Res. 21 (2008) 156-161.

5) M. Morinaga, N. Yukawa and H. Adachi: J. Iron Steel Inst. Japan 72 (1986) 555-562.

6) K. Matsugi, Y. Murata, M. Morinaga and N. Yukawa: Mater. Sci. Eng. A 172 (1993) 101-110.

7) M. Morinaga, N. Yukawa, T. Maya, K. Sone and H. Adachi: Proc. 6th World Conf. on Titanium, (1988) pp. 1601-1606.

8) M. Morinaga, J. Saito and M. Morishita: J. JILM 42 (1992) 614-621.

9) M. Morinaga, Y. Murata and H. Ezaki: Proc. Int. Symp. Material Chemistry in Nuclear Environment, (Tsukuba, March 1992) pp. 241252.

10) R. Ninomiya, H. Yukawa and M. Morinaga: J. JILM 44 (1994) 171177.

11) K. Matsugi, Y. B. Choi and G. Sasaki: J. Japan Inst. Metals 75 (2011) 110-114.

12) H. Tadano, T. Take, M. Fujita and S. Hayashi: Proc. 2nd Int. Conf. on Electromagnetic Processing of Materials, 1 (1997) pp. 377-382.

13) T. Volkmann, W. Loser and D. M. Herlach: Metall. Trans. 28A (1997) 461-469.

14) S. Asai: J. Iron Steel Inst. Japan 7 (2002) 44-48.

15) J. Saito, Y. Takagi, M. Morinaga, Y. Murata and Y. Harada: Proc. 3rd Japan Int. SAMPE Symp., (Tokyo, December 1993) pp. 1252-1257.

16) Y. Harada, M. Morinaga, J. Saito and Y. Takagi: J. Phys. Condens. Matter 9 (1997) 8011-8030.

17) P. Villars and L. D. Calvert: Pearson's Handbook of Crystallographic Data for Intermetallic Phases vol 1-3, (ASM, Metal Park, OH, 1985).

18) K. Matsugi, Y. Murata, M. Morinaga and N. Yukawa: Proc. 7th Int Conf. on Superalloys, ed. by S. D. Antolovich, R. W. Stusrud, R. A. MacKay, D. L. Anton, T. Khan, R. D. Kissinger and D. L. Klarstrom, (TMS, Warrendale, 1992) pp. 307-316.

19) K. Matsugi, T. Endo, Y. B. Choi and G. Sasaki: Mater. Trans. 51 (2010) 740-748.

20) S. Miyazaki and K. Otsuka: ISIJ Int. 29 (1989) 353-377.
21) S. F. Hsieh, S. K. Wu and H. C. Lin: J. Alloy. Compd. 339 (2002) 162166.

22) C. Seeger and P. L. Ryder: Mater. Sci. Eng. A 179-180 (1994) 641644.

23) Y. Chen, H. C. Jiang, S. W. Liu, L. J. Rong and X. Q. Zhao: Mater. Sci. Eng. A 512 (2009) 26-31.

24) Y.-wook Kim, H.-joong Kim and T.-hyun Nam: J. Alloy. Compd. 449 (2008) 134-138.

25) K. Inaekyan, V. Brailovski, S. Prokoshkin, A. Korotitskiy and A. Glezer: J. Alloy. Compd. 473 (2009) 71-78.

26) C. Satto, A. Ledda, P. Potapov, J. F. Janssens and D. Schryvers: Intermetallics 9 (2001) 395-401.

27) J.-hwa Lee, T.-hyun Nam, H.-jun Ahn and Y.-wook Kim: Mater. Sci. Eng. A 438-440 (2006) 691-694.

28) Z. G. Wei and R. Sandstrom: J. Mater. Sci. 33 (1998) 3743-3762.

29) H. Kyogoku, T. Hatakeyama, F. Yoshida, S. Komatsu, T. Sakuma and U. Iwata: Trans. Japan Soc. Mech. Eng. (A) 65-632 (1999) 873-878.

30) H. Kyogoku, T. Kadomura, A. Terayama and S. Komatsu: J. Japan Soc. Powder Powder Metall. 51 (2004) 43-47.

31) J. Askill: Tracer Diffusion Data for Metals, Alloys and Simple Oxides vol 1-3, (IFI, Plenum, NY, 1970) p. 21.

32) M. Morinaga and N. Yukawa: Proc. 1st Int. Conf. on Computer Applications to Materials Science and Engineering, (Yokohama, 1991) pp. 803-808.

33) K. Matsugi, M. Kawakami, Y. Murata, M. Morinaga, N. Yukawa and T. Takayanagi: J. Iron Steel Inst. Japan 78 (1992) 821-828.

34) J. Uchil, K. G. Kumara and K. K. Mahesh: J. Alloy. Compd. 325 (2001) 210-214.

35) S. F. Hsieh, S. L. Chen, H. C. Lin, M. H. Lin, J. S. Huang and M. C. Lin: J. Alloy. Compd. 494 (2010) 155-160.

36) S. L. Chen, S. F. Hsieh, H. C. Lin, M. H. Lin and J. S. Huang: Mater. Sci. Eng. A 445-446 (2007) 486-492.

37) B. Huneau, P. Rog, K. Zeng and R. Schmid-Fetzer: Intermetallics 7 (1999) 1337-1345

38) J. P. Kuang, R. A. Harding and J. Campbell: Mater. Sci. Technol. 16 (2000) 1007-1016.

39) N. Nayan, Govind, C. N. Saikrishna, K. V. Ramaiah, S. K. Bhaumik, K. S. Nair and M. C. Mittal: Mater. Sci. Eng. A 465 (2007) 44-48.

40) C. L. Chu, S. K. Wu and Y. C. Yen: Mater. Sci. Eng. A 216 (1996) 193200.

41) A. M. Chaz, C. Coddet and G. Beranger: J. Less-Common Met. 83 (1982) 49-70

42) D. Caplan and G. I. Sproule: Oxid. Met. 9 (1975) 459-472.

43) M. Morinaga, N. Yukawa and H. Adachi: J. Iron Steel Inst. Japan 71 (1985) 1441-1451.

44) M. Morishita, Y. Ashida, M. Chikuda, M. Morinaga, N. Yukawa and H. Adachi: ISIJ Int. 31 (1991) 890-896. 